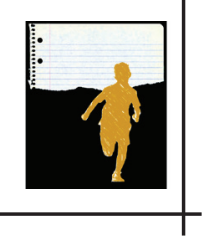

\title{
BRINCADEIRA DE CRIANÇA E CIÊNCIAS POR INVESTIGAÇÃO NA EDUCAÇÃO INFANTIL
}

\author{
Vera Maria de Lima Silva* \\ Orlando Coelho Barbosa** \\ Maria Candida Varone de Morais Capecchi***
}

Resumo: Neste trabalho, é apresentado um recorte de uma dissertação de mestrado voltada para a investigação das possibilidades de aprendizagem de aspectos da cultura científica na educação infantil, a partir dos interesses próprios das crianças em suas brincadeiras. 0 material aqui apresentado compreende a análise de uma roda de conversa em que a professora propõe às crianças a realização de uma investigação, a partir de suas memórias, considerações e questionamentos sobre uma brincadeira muito comum entre elas: fazer bolinhas de sabão. Essa roda de conversa foi realizada na primeira etapa de uma sequência didática elaborada pela professora a partir da observação das ações e enunciações das crianças durante uma brincadeira por elas selecionada em uma aula de artes. Com base nos diversos questionamentos emergentes dessa atividade, é possivel verificar e desmistificar conceitos e preconceitos sobre a infância, o pensamento e a linguagem infantil e sua capacidade de resolução de problemas. A partir da teoria de desenvolvimento de Lev Vygotsky e por meio da identificação de indícios de alfabetização científica e competências científicas nos relatos das crianças, 0 processo evidencia o potencial das brincadeiras infantis, assim como o importante papel mediador da professora na introdução dos pequenos no universo das ciências e a importância de se estabelecerem espaços dialógicos na educação infantil.

Palavras-chave: Educação infantil. Alfabetização científica. Competências científicas. Rodas de conversa. Formação de professores.

\footnotetext{
* Mestra em Ensino, História e Filosofia das Ciências e da Matemática pela Universidade Federal do ABC (UFABC), professora de Educação Básica na rede municipal de São Bernardo do Campo.E-mail:vmdls.14@gmail.com

** Mestre em Psicologia Educacional pelo Centro Universitário Fieo, doutorando em Psicologia Educacional pela mesma instituição com financiamento da Capes. E-mail: ohaicai@gmail.com

*** Doutora em Educação pela Universidade de São Paulo (USP), com doutorado sanduíche na Universidade de Leeds (Inglaterra). Docente da Universidade Federal do ABC (UFABC).E-mail: maria.capecchi@ufabc.edu
} 


\section{APRESENTAÇÃO}

Pensar em infância nos remete a brincadeiras e descobertas e à alegria que aprender algo novo pode representar. É dessa alegria singular, que faz os olhos brilharem e o sorriso leve se desenhar no rosto, que vamos tratar aqui do prazer que uma aprendizagem pode proporcionar... da construção de conhecimentos na educação infantil (EI).

É fato que os pequenos estão descobrindo os significados do seu mundo e se apropriando deles, e, por isso, são naturalmente curiosos, ávidos por descobrir, experimentar, conhecer, aprender. Quanta aprendizagem pode existir numa brincadeira? Quantas descobertas se apresentam nas falas, nos gestos e nos olhares das crianças? Quantos conhecimentos são gestados nessa etapa do desenvolvimento?

Se nos debruçarmos sobre essas questões buscando compreender o que está explícito ou oculto em cada uma dessas ações, podemos nos surpreender com as construções que se avizinham no que parecem ser simples brincadeiras dos pequenos.

E se eles aprendem em momentos livres, o que dizer daqueles pensados para provocá-los, para incitá-los ao conhecimento e à descoberta?

Esta é a nossa proposta: apresentar um recorte de uma pesquisa de mestrado em que foi investigada uma sequência didática (SD) elaborada a partir de uma brincadeira de bolinhas de sabão, escolhida pelas crianças, que provocou tantos questionamentos a ponto de a professora reconhecer que ali estava uma situação intencional de aprendizagem que poderia gerar reflexões, discussões e novas descobertas sobre a construção da aprendizagem de ciências pelos pequenos.

\section{CONVERSANDO À LUZ DE TEORIAS}

Quando pensamos nas crianças da El e na forma como elas se comunicam, seja por meio de fala, gestos, olhares e silêncios, a teoria de Vygotsky não nos passa despercebida. Justamente porque nos remete à reflexão do elo existente entre o que está no pensamento da criança e o que é comunicado por meio da linguagem.

A comunicação da criança com o mundo tem início antes mesmo de ela se apropriar da linguagem falada. Desde o nascimento, o bebê busca estabelecer contato com o meio social e, para isso, usa gestos, sons e olhares na construção desse diálogo. Pela mediação do meio social, a criança passa a atribuir significados a ele. Esse momento é chamado por Vygotsky de fase pré-intelectual no desenvolvimento da linguagem (OLIVEIRA, 2006).

A linguagem tem duas funções básicas: o intercâmbio social, que seria o conhecimento e o uso das ferramentas necessárias para a comunicação naquela cultura, e o pensamento generalizante, que seria a compreensão dos significados e sentidos construídos e socialmen- 
te compartilhados. Esse aspecto faz com que a linguagem se torne instrumento do pensamento (OLIVEIRA, 2006).

Pensamento e linguagem têm origens distintas: o primeiro é biológico e o segundo social; entretanto, mesmo com limiares diferentes, são mediados pela cultura: "Em um determinado ponto, ambas as linhas se cruzam, após o que o pensamento se torna verbal e a fala se torna intelectual" (VYGOTSKY, 2010, p. 246).

Ao pensarmos no uso social da linguagem, precisamos apontar de que maneira o intercâmbio de ideias e o pensamento generalizante acontecem: por meio do significado e do sentido de cada um.
[...] os significados das palavras evoluem. Quando uma palavra nova, ligada a um determi- nado significado, é apreendida pela criança, o seu desenvolvimento está apenas começan- do; no início ela é uma generalização do tipo mais elementar que, à medida que a criança se desenvolve, é substituída por generalizações de um tipo cada vez mais elevado, culmi- nando o processo na formação dos verdadeiros conceitos (VYGOTSKY, 2010, p. 246).

Assim, o significado de uma palavra é o elo entre o pensamento e a linguagem, é a expressão que traduz o pensamento. E ainda, é socialmente construído e possibilita aos membros de uma determinada cultura o intercâmbio social e o pensamento generalizante.

A compreensão dos significados representa um avanço no desenvolvimento do pensamento e da linguagem. Conforme estes são apreendidos, a criança entende aos poucos o sentido e o uso de cada um na linguagem, e, do ponto de vista psicológico, o significado de uma palavra é uma generalização do pensamento (VYGOTSKY, 2010).

Assim, as aprendizagens da criança não têm início na escola, começam muito antes, nas relações que são estabelecidas entre ela, os sujeitos e o mundo que a rodeia.

Trazemos, então, a teoria de Vygotsky que considera o contexto escolar como elemento fundamental no desenvolvimento afetivo, social e mental da criança, uma vez que as vivências ali proporcionadas podem ser organizadas de forma a desencadear aprendizagens que não aconteceriam espontaneamente.

Um dos apontamentos dos estudos dele para explicar o desenvolvimento e as aprendizagens humanas e que observamos com certa facilidade no contexto escolar são as zonas de desenvolvimento cognitivo. A zona de desenvolvimento real diz respeito aos conhecimentos que a criança traz de vivências, experiências e relações com o mundo, e a zona de desenvolvimento proximal seria a ampliação dos conhecimentos anteriores, a partir das intervenções mediadas nas relações construidas com um parceiro mais experiente.

Esse conceito é bastante claro quando pensamos nas relações das crianças com seus pares em momentos diversos da rotina escolar, orientados pelo professor, ou nos momentos de brincadeiras livres. 
Conhecendo as habilidades individuais das crianças, o professor pode agrupá-las de forma intencional, para que as zonas de desenvolvimento propostas por Vygotsky sejam favorecidas. Esses são os chamados agrupamentos produtivos.

\begin{abstract}
[...] aprendizagem não é desenvolvimento; entretanto, o aprendizado adequadamente organizado resulta em desenvolvimento mental e põe em movimento vários processos de desenvolvimento que, de outra forma, seriam impossiveis de acontecer. Assim, o aprendizado é um aspecto necessário do processo de desenvolvimento das funções psicológicas culturalmente organizadas e especificamente humanas [...] os processos de desenvolvimento não coincidem com os processos de aprendizado. Ou melhor, o processo de desenvolvimento progride de forma mais lenta e atrás do processo de aprendizado; dessa sequenciação resultam, então, as zonas de desenvolvimento proximal (VYGOTSKY, 2007, p. 103).
\end{abstract}

Na observação de Vygotsky (2010), o papel do professor é decisivo para todas as aprendizagens que podem ser construídas no espaço escolar. 0 professor é o elemento mediador da relação dialética entre a criança e o conhecimento, atuando como o parceiro experiente naquele contexto e oferecendo o acréscimo de novos desafios ao que o aluno já sabe, possibilitando-Ihe avançar na construção de conhecimentos.

[...] o aprendizado orientado para os niveis de desenvolvimento que já foram atingidos é ineficaz do ponto de vista do desenvolvimento global da criança. Ele não se dirige para um novo estágio do processo de desenvolvimento, mas, em vez disso, vai a reboque desse processo. Assim a noção de zona de desenvolvimento proximal capacita-nos a propor uma nova fórmula, a de que o "bom aprendizado" é somente aquele que se adianta ao desenvolvimento (VYGOTSKY apud PALANGANA, 2005, p. 136).

É preciso, portanto, oferecer situações que desafiem a criança a ir além do que já sabe e, dessa forma, favorecer o avanço das funções psicológicas elementares para as funções superiores, acrescendo-Ihes novas aprendizagens e referências para outras aquisições (REG0, 2014).

A vivência proporcionada pela escola é decisiva no desenvolvimento das aprendizagens do sujeito. Um dos aspectos que nos auxiliam nessa análise é conhecer os apontamentos de Vygotsky acerca dos conceitos científicos e cotidianos, por ele assim chamados.

Os conceitos cotidianos são construidos na história pessoal do sujeito, nas observações, interpretações e situações concretas vivenciadas. Um processo que não requer instrução ou sistematização, porque a criança aprende com o outro nas experiências sociais das quais participa.

Os conceitos cotidianos funcionam como mediadores para a construção dos conceitos científicos, uma vez que se originam das representações que o sujeito tem do mundo. 
Os conceitos espontâneos ou cotidianos precisam ser explorados de forma exaustiva na primeira infância, possibilitando que a criança investigue todas as alternativas e indagações que julgue necessárias (POZO, 2012). É fundamental que a curiosidade peculiar à criança pequena possa, pouco a pouco, ser alimentada por respostas que gerem outras perguntas, de modo que, nesse encadeamento de conhecimentos, os conceitos científicos aflorem, sem a perda da curiosidade e do questionamento.

Acreditamos que indicar essas ideias de Vygotsky nos dão subsídios para relacioná-las com as aprendizagens na El, ampliando as possibilidades de discussão e compreensão do processo de construção de conhecimentos nesse segmento de ensino.

\title{
ALFABETIZAÇÃO CIENTÍFICA E EDUCAÇÃO INFANTIL
}

A palavra alfabetizar nos remete à ideia de aquisição da competência de leitura e escrita da língua pátria. Tomamos aqui a concepção de Paulo Freire (1996, p. 9) de que aprender uma língua é muito mais que decifrar os códigos do signo:

\begin{abstract}
A leitura do mundo precede a leitura da palavra, dai que a posterior leitura desta não possa prescindir da continuidade da leitura daquele. Linguagem e realidade se prendem dinamicamente. A compreensão do texto a ser alcançada por sua leitura crítica implica a percepção das relações entre o texto e o contexto.
\end{abstract}

Para se tornar um escritor e leitor nos parâmetros propostos por Freire, é necessário que essa leitura e essa escrita tenham um sentido para seu escritor/leitor e que ele possa significá-las nas suas vivências, compreendendo o alcance das suas construções e transformações no meio histórico-cultural.

A ideia de alfabetização científica (AC) apresentada por Delizoicov e Lorenzetti (2001) aponta similaridade com o entendimento de Freire sobre alfabetização. Esses autores propõem que a AC seja compreendida como processo pelo qual a linguagem das ciências adquire significados, constituindo-se um meio para que o indivíduo possa ampliar o universo de conhecimentos na sua cultura, como cidadão socialmente inserido.

Compreendemos que as interligações entre conhecimento e mudança de atitude podem colaborar para a formação de um sujeito agente transformador da sociedade e não um mero reprodutor de conceitos científicos, que, muitas vezes, sequer compreende.

Para Lucia Sasseron e Anna Maria Pessoa de Carvalho (2008), a AC refere-se a ensinar ciências para além dos conteúdos conceituais elencados nas propostas curriculares, numa perspectiva que envolve alunos e professores em questões que fazem parte do processo científico, como investigações, discussões e experimentações. 
As autoras supracitadas propõem como indicadores da AC (IAC) habilidades observadas no trabalho de investigação científica que possibilitam ações direcionadas à resolução de um problema. Essas habilidades estão divididas em três blocos:

- Obtenção de dados: 1. seriação da informação; 2. organização da informação; 3. classificação da informação.

- Organização das ideias: 4. raciocínio lógico: desenvolvimento e apresentação das ideias e como são comunicadas; 5 . raciocínio proporcional: maneira como variáveis têm relações entre si, ilustrando a interdependência que pode existir entre elas.

- Compreensão da situação analisada: 6. levantamento de hipóteses; 7. teste de hipóteses; 8. justificativa; 9. previsão; 10. explicação e análise (SASSERON; CARVALHO, 2008).

Encontramos nesses indicadores aspectos semelhantes ao que é proposto nas Diretrizes Curriculares Nacionais para a El, que propõem para a área de ciências uma prática pedagógica que garanta experiências que "incentivem a curiosidade, a exploração, o encantamento, o questionamento, a indagação e o conhecimento das crianças em relação ao mundo físico e social, ao tempo e à natureza" (BRASIL, 2010, p. 26).

Posicionamento semelhante encontramos em Melina Furman (2009), na defesa de um ensino que privilegie dois aspectos da ciência: como produto, conjunto de saberes, fatos, conceitos e explicações produzidos ao longo do tempo, e como processo, que diz respeito a procedimentos.

Furman (2009, p. 12) propõe que ensinar competências científicas (CC) na escola básica é fundamental e cita algumas delas:

- Observar com um propósito (procurando padrões ou raridades).

- Descrever o que se observa.

- Comparar e classificar, com critérios próprios ou dados.

- Formular perguntas investigativas.

- Propor hipóteses e previsões.

- Planejar experimentos para responder a uma pergunta.

- Analisar resultados.

- Propor explicações para os resultados e elaborar modelos que se ajustem aos dados obtidos.

- Procurar e interpretar informações científicas de textos e outras fontes.

- Argumentar com base em evidências.

- Escrever textos no contexto das ciências. 
A escolha desse referencial considerou as especificidades da faixa etária em questão, momento em que as crianças estão buscando apropriação dos significados das coisas do mundo que as rodeia. A ideia de "estabelecer as bases do pensamento científico" desde cedo nos pareceu apropriada porque valoriza o olhar da criança para suas observações sobre o mundo, além de incentivá-la a aprimorá-lo. Visto que a El é um tempo singular do desenvolvimento que integra aprendizagens sociais, afetivas e cognitivas, consideramos que este trabalho traz como contributo um olhar para as descobertas infantis que podem ser proporcionadas no espaço escolar, respeitando-se o desenvolvimento próprio da faixa etária e, ao mesmo tempo, valorizando e aguçando a curiosidade peculiar da criança pequena.

Paulo Freire (1989, p. 10), ao citar as leituras de mundo que cada um de nós realiza desde pequeno, traduz com beleza esse percurso, apontando que há sinais passiveis de observação ao nosso redor e, também,

[...] na dança das copas das árvores sopradas por fortes ventanias que anunciavam tempestades, trovões, relâmpagos; as águas da chuva brincando de geografia: inventando lagos, ilhas, rios, riachos. Os "textos", as "palavras", as "letras" daquele contexto se encarnavam também no assobio do vento, nas nuvens do céu, nas suas cores, nos seus movimentos; na cor das folhagens, na forma das folhas, no cheiro das flores - das rosas, dos jasmins -, no corpo das árvores, na casca dos frutos. Na tonalidade diferente de cores de um mesmo fruto em momentos distintos: o verde da manga-espada verde, o verde da manga-espada inchada; o amarelo esverdeado da mesma manga amadurecendo, as pintas negras da manga mais além de madura. A relação entre estas cores, o desenvolvimento do fruto, a sua resistência à nossa manipulação e o seu gosto.

Ousamos aproximar a construção de conhecimentos na área de ciências pela criança pequena da poesia empregada por Freire, quando, mesmo sem nomear ou perceber quanto de cientificidade (em certa medida) há por trás delas, aponta um processo inicial de construção que engloba a percepção e leitura dos sinais do mundo, evoluindo aos poucos para a significação e contextualização deles.

A curiosidade, a descoberta e a busca de respostas são próprias do ser humano, especialmente dos pequenos, que estão, nesse momento, construindo suas impressões e ideias sobre o mundo que os cerca e onde vivem, e, geralmente, são muitas as perguntas que querem ver respondidas.

Mesmo sem estudar ciências, toda criança tem um pouco de cientista desde o berço, "cientista intuitivo" (POZO, 2012), que, ao explorar o meio, faz considerações sobre as observações e sensações que tem tanto de objetos físicos como de fenômenos presentes no seu cotidiano. 
As palavras de Pozo (2012), porém, não devem ser tomadas como uma apologia do "ensino por descoberta". Para o autor, os conceitos científicos fazem parte de uma extensa teia de relações, muito além da possibilidade de representação pelas crianças pequenas, mas que, se discutidos desde cedo, aguçam o pensamento, dão significado à ciência intuitiva que trazem do berço e permitem ampliá-la em novos e estruturados conhecimentos no futuro, e isso se estende para as diferentes áreas do conhecimento.

0 universo científico está intrinsecamente ligado ao universo lúdico. Ambos são espaços de possibilidades, investigação, autoria, autonomia, construção de conhecimento e subjetividade. Por isso, é cada vez mais urgente que a escola de Educação Infantil assuma uma concepção de ensino que não separe o raciocínio da imaginação (KLISYS, 2010, p. 13).

De maneira simples, Klisys (2010) trata da necessidade de ensinar ciências na El com uma finalidade que não seja exclusiva para esse universo, mas que mantenha um diálogo com o meio em que o indivíduo se insere. Acreditamos que essa ideia, além de favorecer a construção de conhecimentos dos assuntos das ciências pelos pequenos, colabora principalmente para a elaboração de explicações e de novos questionamentos, e, assim, ao ampliar as relações desses significados com outras áreas do conhecimento, auxilia também o entendimento do mundo pelas crianças.

0 ensino de ciências na El tem passado por reformulações significativas ao longo do tempo, bem como as concepções acerca dessa modalidade. Os documentos oficiais norteadores dos currículos apontam para a construção de um ensino em que os saberes, as vivências e as leituras de mundo dos pequenos sejam valorizados. Além de buscar responder aos seus questionamentos sobre os fenômenos que observam, a proposta é levá-los a encontrar explicações por meio de modos variados de representação, para que possam compreendê-los como parte de um contexto e não isoladamente (BRASIL, 1998).

Ora, se afirmamos anteriormente que as crianças são curiosas, querem descobrir, conhecer... um ensino favorável deve partir da valorização dessas características e proporcionar o questionamento, a observação, a comunicação de ideias, a experimentação, a discussão de resultados além do registro das vivências.

Para uma criança aprender os conteúdos relativos às ciências é preciso que ela continue pensando sobre os fenômenos e seja encorajada a desenvolver "teorias" sobre eles, a estabelecer relações, buscar a diferenciação existente entre mitos, lendas, explicações provenientes do senso comum e conhecimentos científicos. 0 trabalho na creche ou na escola deve, então, ser voltado à ampliação das experiências que as crianças já possuem e para a construção de novos conhecimentos que as aproximem das diversas formas de explicar o mundo (HUBNER, 2001). 
Também a ideia de Selma Fuentes (2012) sobre o ensino da área com os pequenos nos auxilia a compreender a necessidade de sua abordagem desde cedo. Para ela, ensinar ciências desde a El visa despertar a curiosidade, provocar a busca de respostas e a compreensão do porquê das coisas, desenvolver o pensamento crítico, aguçar a inteligência, criar situações em que as ideias pessoais possam ser confrontadas com a experiência prática, de forma significativa e lúdica, permitindo que novos conhecimentos sejam agregados a outros já existentes. Talvez assim o encantamento com novas descobertas possa acontecer e permanecer, fazendo surgir desejos de outras buscas por novos saberes.

\section{OBSERVANDO BOLINHAS DE SABÃO}

Segundo Maria Cecilia Minayo (2001, p. 14), a metodologia é como "o caminho do pensamento", numa alusão à descrição do desenvolvimento do processo empreendido na investigação pelo pesquisador.

Mas no que consiste uma pesquisa? Podemos dizer que ela nasce de uma dúvida, e ao mesmo tempo da certeza de que é possivel encontrar respostas que contemplem os questionamentos ou que ajudem a esclarecê-los.

É necessário pontuar ainda que a conclusão da pesquisa não encerra a busca de respostas, porque, no decorrer do seu desenvolvimento, podemos nos deparar com novas questões. Tal qual o conhecimento, a pesquisa nunca é um fim em si mesma.

Segundo Minayo (1993), uma pesquisa qualitativa não é apenas uma atividade científica que usa metodologias próprias para respaldá-la; ela busca investigar dados da realidade que não podem ser quantificados, mas que podem ser compreendidos na dinâmica das relações sociais. E ainda,

[...] a pesquisa é uma atitude e uma prática teórica de constante busca que define um processo intrinsecamente inacabado e permanente. É uma atividade de aproximação sucessiva da realidade que nunca se esgota, fazendo uma combinação particular entre teoria e dados (MINAYO, 1993, p. 23).

Isso nos remete aos primeiros desenhos da pesquisa, da qual foi extraído este artigo, que surgiram no início de um ano letivo, ao mesmo tempo que a professora, uma das autoras, iniciou o mestrado. A experiência docente fazia a professora acreditar que as práticas oferecidas na El favoreciam a AC, e, por essa razão, sua observação e atenção nas discussões e proposições das crianças estavam muito afloradas, em busca de evidências para sustentar sua hipótese. Podemos dizer que o olhar atento na busca de observáveis constituiu o primeiro momento da pesquisa. 
0 trabalho aqui descrito começa a germinar nas aulas de artes e de informática. 0 objetivo era que as crianças conhecessem e aprendessem brincadeiras tradicionais infantis, na maioria das vezes distantes do cotidiano atual, e depois, em duplas, escolhessem uma para aprender a brincar. 0 artista escolhido era Ivan Cruz, que retratava em pinturas diversas situações de brincadeiras tradicionais.

Elas aprenderiam a brincar e, tendo a professora como escriba, elaborariam um texto explicativo sobre a brincadeira. 0 texto das crianças e os desenhos elaborados por elas iriam compor um livro eletrônico de brincadeiras tradicionais, a ser publicado no blog da escola.

Durante uma pesquisa no site do artista, uma criança sugeriu que fizessem bolinhas de sabão, ideia acatada por toda a turma. Cumprindo o que o planejamento de artes previa, a professora achou uma ótima ideia, mais uma brincadeira para explorar. Tratou, então, de organizar o material para que, em outro dia, fossem brincar na quadra da escola.

No dia combinado, lá se foi a turma para a quadra, usando um brinquedo próprio vendido em lojas comuns e copinhos com água misturada com detergente, para a confecção das bolinhas.

Eis que o detergente transparente usado incialmente pela professora acabou e o disponível para reposição naquele momento era amarelo. Enquanto preparava um pouco mais de mistura, uma criança prontamente disse: "Agora a bolinha vai sair amarela".

Foi o suficiente. Todos queriam ver a bolinha amarela. Alguns jogaram fora a água transparente que tinham para brincar com a nova mistura. Mas a bolinha não era colorida. Decepção? Não. A brincadeira continuou e as crianças brincavam agora com outra hipótese: queriam ver se as bolinhas eram amarelas, sopravam e acompanhavam o flutuar delas tentando detectar a mesma cor da mistura que usavam.

Enquanto buscavam as bolinhas coloridas, as crianças reclamavam porque elas estouravam logo e porque algumas eram muito pequenas. A professora questionava algumas crianças sobre a cor das bolinhas, e elas tinham hipóteses bem interessantes: que estouravam depressa, então não era possível ver a cor ou então que o amarelo era muito "clarinho" e, por isso, a cor não aparecia.

A brincadeira demorou mais que o previsto. A professora seguia ouvindo as falas das crianças e o olhar delas maravilhado, enquanto corriam atrás de bolinhas flutuando.

Naquele momento, diante da reação das crianças à brincadeira e do visível interesse demonstrado por uma atividade que já haviam vivenciado outras vezes, a professora pensou que aquela seria uma experiência muito rica para discutir com elas.

Não bastasse isso, uma criança propôs que fizessem "águas coloridas", relembrando uma atividade realizada no início do ano para um estudo sobre cores primárias, em que haviam misturado água com corantes de diversas cores: verde, roxo, azul, laranja, entre outras.

Todo aquele entusiasmo e questionamentos, surgidos a partir de uma observação que poderia passar despercebida, fizeram ecoar, na pesquisadora que já habitava na professora, 
um sinal de alerta para aquela situação. E como ela buscava indícios de aprendizagem de ciências em todas as oportunidades, aquela aula causou-Ihe inquietação. Afinal, como deixar de lado o interesse inesperado provocado por aquela atividade?

Retornando à sala de aula, as crianças desenharam como haviam brincado naquele dia. Quando terminavam as produções, a professora ia expondo os desenhos num painel da sala. Ao final, ela propôs que cada um olhasse com atenção os desenhos dos colegas tentando imaginar o momento da brincadeira que estava registrado ali e compartilhasse com a turma o que havia feito.

Alguns falaram sobre a brincadeira e outros mostraram seus desenhos. A professora foi trazendo para a conversa o que havia ouvido das crianças e entre elas enquanto brincavam na quadra. Observou também que, à medida que algumas crianças falavam sobre o tamanho das bolinhas que haviam feito, as cores, a quantidade de bolinhas obtidas num único sopro ou o formato delas, outras participavam da conversa apresentando seus pontos de vista a partir da fala dos colegas.

Naquele momento, elas tinham muitas questões a serem respondidas, e a ideia de aproveitar a curiosidade e o interesse que a atividade despertava fez a professora acreditar na possibilidade de buscarem juntos as respostas para aquelas dúvidas, usando uma atividade escolhida pelas crianças.

Carvalho (2014, p. 6) toma a frase de Bachelard (1938 apud CARVALHO, 2014, p. 89): "Todo conhecimento é resposta a uma questão" e, sobre ela, completa que "para ser uma questão para os alunos deve estar vinculada a sua cultura". Nesse entendimento, naquele contexto, as questões que se apresentavam ali eram muito significativas para as crianças e para a professora, portanto passiveis de investigação.

A realização dessa atividade favoreceu uma observação mais detalhada dos conhecimentos das crianças sobre o assunto. Ademais, dar continuidade a ela seria uma oportunidade para verificar se esses saberes apresentavam ou não indícios de conhecimentos e relações com assuntos de natureza científica, que poderiam ser esclarecidos e ampliados de acordo com as possibilidades individuais e nas trocas com os pares.

Convencida de que havia ali elementos suficientes para que essa atividade pudesse compor a pesquisa de mestrado e encantada pelo interesse inesperado das crianças, surgia naquele momento uma pesquisadora de fato.

John W. Creswell (2010) aponta que a pesquisa qualitativa busca explicar comportamentos e atitudes e apresenta como características dessa abordagem: a ocorrência dela no cenário natural; a coleta de dados feita por meio do uso de métodos múltiplos e variáveis; o caráter interpretativo presente na análise dos dados; e o aspecto holístico dos fenômenos observados. Para ele, essa abordagem permite ao pesquisador compreender não apenas a situação da investigação, mas também os sujeitos envolvidos e suas relações e interpretações nesse contexto. 


\section{EXISTEM BOLINHAS DE SABÃO QUADRADAS?}

Com a intenção de investigar a construção de conhecimentos sobre ciências pelas crianças, a professora/pesquisadora elaborou um plano de trabalho que buscava integrar o aspecto lúdico da brincadeira por elas escolhida e o caráter investigativo que identificou, de forma latente, na intencionalidade com que exploravam os materiais durante a brincadeira, dando novo sentido a ela. Para aliar os interesses das crianças em relação às bolinhas de sabão e suas intenções de ensino de ciências, caberia à professora oferecer o suporte necessário para que as crianças pudessem explorar suas indagações, por meio da vivência de ações ligadas às práticas científicas (observação, levantamento de hipóteses, previsão, experimentação, verificação e discussão de resultados), aceitando e validando que suas dúvidas e interesses eram genuínos.

Considerando que a compreensão de conceitos científicos formais pelos alunos da El não era a tônica dessa proposta, a intenção era proporcionar às crianças a vivência de uma atividade cotidiana, organizada para uma finalidade além do lúdico: uma pesquisa. E que, nessa empreitada, fossem desafiadas a observar os detalhes, que em outra organização da rotina passariam despercebidos.

Assim, buscando conferir a autoria da ideia e da motivação da atividade às crianças, a partir de suas conversas durante a brincadeira realizada no início do ano, a professora elaborou três questões que norteariam a realização de uma SD a ser desenvolvida nas aulas de artes e de ciências:

1) As bolinhas ficam coloridas quando usamos águas coloridas?

2) Ao acrescentar glicerina ou xarope de milho na água, as bolinhas demoram mais para estourar?

3) Podemos fazer bolinhas de sabão de formatos diferentes?

A SD foi proposta em cinco etapas, todas registradas em áudio/vídeo, fotografias, anotações da professora, registros coletivos com preenchimento de tabela, além de registros individuais das crianças na forma de desenho e/ou pintura ao final de cada etapa. As produções das crianças compuseram um painel, em que cada uma foi convidada a expor suas produções aos colegas e familiares e que podiam visitar no momento de saída da escola.

- Etapa 1: Apresentação da proposta às crianças e levantamento de seus conhecimentos sobre o tema por meio de roda de conversa.

- Etapa 2: Preparação de mistura de água com corantes, seguida de roda de conversa.

- Etapa 3: Brincadeira de bolinhas de sabão para observar a durabilidade das bolinhas (materiais e equipamentos preparados pela professora do laboratório de informática), seguida de roda de conversa. 
- Etapa 4: Confecção de brinquedo para fazer bolinhas de sabão e escolha livre de um brinquedo a ser usado na brincadeira, com o confeccionado pelas crianças.

- Etapa 5: Brincadeira final com os brinquedos confeccionados pelas crianças e outros escolhidos por elas, seguida de roda de conversa.

\section{BOLINHAS DE SABÃO EXPLODEM AO OLHAR}

Apresentamos a seguir alguns episódios destacados da roda de conversa realizada na primeira etapa da SD, quando a professora retoma a brincadeira de bolinhas de sabão realizada pelas crianças no início do ano letivo e propõe uma investigação num trabalho orientado. Procurando respeitar os aspectos peculiares da faixa etária aqui tratada, buscamos uma discussão atenta a falas, gestos, atitudes e comportamentos ante as propostas da professora, tomando como referenciais para a análise desse processo a teoria de desenvolvimento de Vygotsky, as CC de Furman (2009) e os indicadores de AC de Sasseron e Carvalho (2008).

\section{Episódio 1.1}

No início deste episódio, as crianças comunicam suas ideias sobre investigação, construidas em vivências pessoais e com diferentes linguagens: livros, revistas, televisão, computador etc. Nesse processo, detalham procedimentos que remetem a ações de um detetive, como uma pessoa que procura desvendar segredos, segue pegadas, usa lupas: turnos $6,7,10,12$.

1. Prof.: Turma, lembra que nós fizemos uma investigação na escola? Quem lembra como se faz uma investigação?

2. AP: Vendo as coisas que a gente quer fazer.

3. AH: Também é olhar o que a gente vai fazer.

4. Prof.: Investigação é olhar o que a gente vai fazer?

5. AH: Hum hum.

6. AK: É quando a gente acha uma coisa, a gente não sabe e a gente tenta descobrir o que é.

7. AW: É "investi" as pegadas (faz um gesto como se tivesse uma lupa).

8. Prof.: Investigar é procurar as pegadas?

9. AW: É.

10. AX: Procurar coisas.

11. Prof.: Eu não entendi, como assim procurar as pegadas?

12. AK: Tem que ser caminhando senão perde as pegadas. 
As crianças não comunicam suas ideias somente por meio da fala, usam diversas linguagens e, muitas vezes, "falam com o corpo" (VELANGA, 2008, p. 164). No turno 7, ao dizer que investigação "É 'investi' as pegadas (faz um gesto como se tivesse uma lupa)", a criança usa a linguagem gestual para assegurar a compreensão do que diz.

Nos turnos 13 a 15, observamos que a professora questiona o grupo sobre o processo de investigação, e uma criança faz um apontamento que acrescenta uma nova reflexão aos nossos dados.

13. Prof.: E se não tiver pegadas na nossa investigação? Como a gente vai encontrar alguma coisa?

14. Crianças em dúvida: dizem sim e não.

15. AH: A gente vai desenhando.

16. AK: Vai olhando com a lupa.

17. AP: Se não tem lupa, a gente vai ter que ficar aqui.

0 desenho é a primeira forma de registro escrito feito pela criança (VYGOTSKY, 2010). Podemos então sugerir que, ao fazer essa proposta, a criança AH esteja justamente interessada em registrar seu percurso como uma forma de auxiliar na investigação empreendida. Essa mesma criança já havia feito referência ao percurso/processo envolvido no ato de investigar no turno 3, quando afirmou que investigação "Também é olhar o que a gente vai fazer".

À medida que a professora vai fazendo a mediação da conversa, instigando-as a refletir sobre suas ideias, as crianças começam a organizar o pensamento, fazendo um resgate de memória das vivências referentes àquele contexto. Até que uma criança relaciona as falas dos colegas ao trabalho do cientista (do turno 20 ao 25). Essa negociação de sentidos acontece porque elas refletem sobre o que falam e relacionam isso ao que ouvem e pensam (WARSCHAUER, 2001).

Podemos observar no turno 20 que $A B$, após ouvir os colegas, sintetiza o que os outros estavam tentando explicar até o momento e traz um novo dado à conversa: "É igual um cientista faz". Esse apontamento resulta das leituras de mundo que essa criança fez e revela que não é uma mera afirmação. Ao dizer isso, ela elaborou e deu um novo significado aos conceitos de detetive e de cientista: ambos procuram coisas, os dois querem descobrir, mas o detetive encontra algo oculto e o cientista descobre algo novo.

18. Prof.: Mas se eu não tiver lupa posso fazer investigação?

19. AP: Não sei.

20. AB: É igual cientista faz.

21. Prof.: É igual um cientista faz? E como que um cientista faz? Me explica...

22. $\mathrm{AB}$ : Ele mistura as coisas e faz outras coisas. 
23. Não identificado: $E$ ele vê as coisas.

24. Prof.: E se não tem pegadas? Como que ele descobre?

25. $\mathrm{AB}$ : Tem pistas.

26. Prof.: 0 AB disse que investigação é igual um cientista faz. Não foi isso que você falou? (pergunta à criança, que confirma com a cabeça). E se ele não tem pegadas, ele tem pistas... Nós temos aqui algumas pistas pra nossa investigação. Vocês contaram pra prof. que investigar é procurar alguma coisa, descobrir alguma coisa. Quando eu vou fazer uma investigação, significa que eu quero saber alguma coisa que eu ainda não sei e ai a gente vai investigar, a gente vai pesquisar, a gente vai procurar.

Aqui é fundamental pontuar o estabelecimento de sentido feito pelas crianças. Se a professora tivesse iniciado a conversa caracterizando e diferenciando detetive e cientista, $A B$ permaneceria com suas ideias prévias. Possibilitar que as crianças coloquem em jogo seus saberes e busquem justificá-los é fundamental para o desenvolvimento de habilidades mentais superiores, como o raciocínio lógico, a capacidade de análise e síntese, memória voluntária e argumentação (VYGOTSKY, 2010, p. 90).

No turno 26, a professora resgata as ideias das crianças para compartilhar o significado que está sendo formulado para investigação. Observamos nesse momento um dos objetivos da roda de conversa na El, que é o sentido de coletividade. A partir daquele momento, a ideia de fazer uma investigação passa a ser compartilhada com o grupo.

Essa comunicação de vivências e a retomada das informações são elementos necessários para que as aprendizagens infantis ocorram com sucesso. Nesse sentido, os Referenciais Curriculares Nacionais para a Educação Infantil (Rcnei) propõem que o professor considere

Os conhecimentos das crianças sobre o assunto a ser trabalhado: a interação das crianças com os adultos, com outras crianças, com os objetos e o meio social e natural permitem que elas ampliem seus conhecimentos e elaborem explicações e "teorias" cada vez mais complexas sobre o mundo. Estes conhecimentos elaborados pelas crianças oferecem explicações para as questões que as preocupam. São construções muito particulares e próprias do jeito das crianças serem e estarem no mundo. É fundamental considerar esses conhecimentos, pois isso permite ao professor planejar uma sequência de atividades que possibilite uma aprendizagem significativa para as crianças, nas quais elas possam reconhecer os limites de seus conhecimentos, ampliá-los e/ou reformulá-los (BRASIL, 1998, p. 30).

Nesse episódio, evidencia-se a visão das crianças sobre "investigação" construida no senso comum. Nessa faixa etária, elas estão se apropriando de interpretações sobre o mundo que as cerca, e, muitas vezes, o sentido de uma palavra pode remetê-las à compreensão de 
um outro significado. Enquanto a professora fala de investigação pensando no cientista, as crianças imaginam investigação feita por um detetive, policial ou outras referências que tenham.

Embora haja alguma semelhança nas ações envolvidas nesses dois campos, na ciência o principal ponto a destacar é que, por mais que nos aproximemos de uma resposta, há sempre a possibilidade de sua refutação. É importante diferenciar cientista de investigador, uma vez que a investigação policial é também científica e essa é uma informação que pode ser relevante nas construções de conhecimento de mundo pela criança. 0 que diferencia os dois é o objeto de estudo, e isso acaba trazendo diferentes entendimentos aos procedimentos envolvidos. Enquanto o investigador policial procura encontrar pistas sobre algo já dado, algo que de fato ocorreu, o cientista procura criar teorias para explicar o mundo natural.

\section{Episódio 1.2}

0 diálogo apresentado a seguir é a continuidade do trecho anterior, mas observamos agora que a conversa assumiu um novo contexto. As crianças já compartilham o sentido do que seria investigação e associam sua realização ao cientista. Para algumas delas, certas qualidades são necessárias e comuns a ambos (detetive e cientista).

\footnotetext{
27. AW: Ele tem que ser muito esperto.

28. Não identificado: Corajoso...

29. AR: Inteligente (faz sinal de inteligente tocando a cabeça com o dedo).

30. AB: Tem que ser bem corajoso.
}

Segundo Vygotsky (2010, p. 48), "para as crianças muito pequenas, pensar significa lembrar", e, conforme vão crescendo, é possivel observar que há uma estreita relação entre essas duas funções.

Nesse sentido, a criança associa o significado de uma palavra a alguma caraterística marcante que esta Ihe remeta. Por exemplo, o pensador diz ainda que, ao perguntar a uma criança o significado da palavra avó, ela responde dizendo "que tem colo macio". A essa relação estabelecida pela criança, Vygotsky (2010, p. 48) dá o nome de lembrança concreta. 0 vínculo entre lembrar e pensar relaciona-se a três aspectos: a lembrança concreta, as lembranças visuais e o significado formulado para a palavra até aquele momento.

Podemos concluir que, da mesma forma como a criança usou uma qualidade particular e pessoal para definir a avó, as crianças atribuíram ao detetive e ao cientista o que consideram como características necessárias para definição de ambos. 


\section{Episódio 1.3}

No episódio apresentado, o destaque é para a participação do aluno AS, em sua primeira manifestação desde o início da SD.

31. AS: Eu acho que pode ser assim... se... lá em casa eu tenho uma bolinha de sabão, aí brinco assim de fazer bolha, ai se ela não sair eu pego outra coisa pra fazer uma bolinha, ai se ela explode eu sopro mais devagar.

32. Prof.: Você acha que se usar o material certo e soprar devagar a bolinha dura mais?

33. AS: É se ele é pequeno a bolinha sai mais devagar e fica mais enorme, eu acho que é assim.

No turno 31, AS, que permaneceu apenas observando e em silêncio o tempo todo, decide explicitar sua hipótese e já se coloca no papel de investigador, relatando e, ao mesmo tempo, analisando sua experiência de brincar com bolinha de sabão em casa. Nesse caso, a criança faz uma sintese de ideias, relacionando o que ouviu com o que sabia até então. Assim, compara e classifica, com critérios próprios ou dados (CC), e essa comparação é baseada nas referências que ela tem. Para tal, define seus critérios, afirmando que tenta usar um brinquedo especifico para fazer a bolinha de sabão, mas que, se não dá certo, vai procurar outro. Provavelmente, baseada nas vivências que teve e validou.

Ainda nesse turno, AS apresenta dados empíricos provenientes da sua experiência com bolinhas de sabão em casa. 0 papel da professora no turno 32 é transformar tais observações em hipóteses a serem investigadas, ajudando a criança a identificar variáveis contidas em sua afirmação, relacionadas à produção de bolinhas de sabão. A criança, por sua vez, reelabora sua convicção, colocando em evidência as variáveis indicadas - formato do objeto e intensidade do sopro -, e utiliza um raciocínio proporcional (IAC) para relacioná-las ao tamanho das bolinhas produzidas (turno 32).

\section{Episódio 1.4}

Neste episódio, as crianças começam a falar sobre a cor das bolinhas de sabão. Na primeira brincadeira, algumas afirmavam que a água, sendo colorida, as bolinhas também o seriam, referindo-se à cor da água, após a adição de detergente amarelo. Vale destacar que o novo tema da conversa é levantado espontaneamente por uma criança.

34. AM: Tem que prestar bastante atenção prof. pra ver a bolinha tá colorida.

35. AG: Ela não tá.

36. AH: Tem um monte de garrafas com... com aquelas águas verde, vermelha... lembra?

37. Prof.: Sim eu lembro. 
38. AR: Isso que eu ia falar... da água colorida...

39. Prof.: Puxa que legal! Vocês lembram da investigação que nós fizemos pra misturar cores. E agora, que tal se nós fizermos as águas coloridas de novo pra investigar uma coisa das bolinhas de sabão?

No turno 34, AM ressalta a importância da observação atenta para perceber um fenômeno, configurando a CC: observar com propósito, procurando padrões ou raridades. Sem saber nomear, ele aponta a observação, que é uma das ações fundamentais no trabalho do cientista. Podemos dizer que, nesse momento, esse aluno expressa sua leitura de mundo (FREIRE, 1989, p. 10) construída na prática e na observação que o ajuda a compreender quem seria um investigador e as qualidades necessárias para sua conceituação.

A hipótese de que as bolinhas ficarão coloridas se a água também estiver colorida não é consenso entre as crianças, conforme observamos no turno 35, mas essa ideia não gera conflitos nem certezas, e as crianças prosseguem relembrando suas experiências.

No turno 36, AH relembra que foi feita uma atividade para que a água ficasse colorida: "Tem um monte de garrafas com... com aquelas águas verde, vermelha... lembra?". Em seguida, a professora sugere incorporar essa vivência ao novo trabalho (turno 39): "Puxa que legal! Vocês lembram da investigação que nós fizemos pra misturar cores?", reorganizando o que haviam feito até aquele momento e, na sequência, valoriza, indiretamente, a divergência entre as afirmações de AM e AG (turnos 34 e 35), trazendo à tona uma questão para investigação: "E agora, que tal se nós fizermos as águas coloridas de novo pra investigar uma coisa das bolinhas de sabão?".

Entre os turnos 40 e 44, observamos que algumas crianças acreditam que a bolinha não assume a cor da água. Na concepção de $\mathrm{AH}$, observada entre os turnos 42 e 46, é mantida a hipótese de que, se a cor da água for escura, a bolinha acompanhará essa cor. Neste episódio, as crianças fazem hipóteses sobre a cor das bolinhas (IAC e CC).

40. Prof.: Puxa que legal! Vocês lembram da investigação que nós fizemos pra misturar cores. E agora, que tal se nós fizermos as águas coloridas de novo pra investigar uma coisa das bolinhas de sabão?

41. AW: Ela vai ficar colorida?

42. Prof.: Eu não sei...

43. $\mathrm{AH}$ : Vai sim se a gente deixar a cor escura.

44. AR: Eu acho.

45. $A B$ : Acho que não muda nada.

46. Prof.: Bom, essa é a primeira parte da nossa investigação: descobrir se as bolinhas vão ficar coloridas no céu. Mas não é só. Lembra que vocês disseram naquele dia que elas estouram muito depressa e não dá pra ver a cor?

47. AH: Sim, mas se a água tiver forte dá. 
Para estabelecer relações tão abstratas como a variação da cor da bolinha, a partir da intensidade da pigmentação da água, seriam necessários conhecimentos específicos muito além da compreensão das crianças no momento. Entretanto, o senso comum faz com que acreditem que existe uma relação entre a intensidade da cor da água e a percepção da cor nas bolinhas que serão produzidas. Não vemos bolinhas de sabão coloridas no sentido apresentado aqui, de uma cor específica no cotidiano, mas vemos bolinhas multicoloridas, dependendo da forma de incidência da luz sobre elas.

Sobre isso, Pozo (2012) aponta que é preciso possibilitar situações em que a criança investigue exaustivamente seus conhecimentos cotidianos para que, futuramente e aos poucos, tenha argumentos para questioná-los e até ampliá-los para conhecimentos científicos.

Como já apontado anteriormente, a El não tem como objetivo que a criança nomeie fenômenos ou elabore explicações causais. Esse é um processo de construção lenta que, se alimentado desde cedo, acreditamos que poderá ser observado no futuro.

Na sequência, as crianças continuam rememorando suas vivências, agora com maior direcionamento da professora, que procura trazer as questões que identificou para desenvolver a investigação.

\section{Episódio 1.5}

Neste episódio, as crianças falam sobre o formato das bolinhas, narrando suas experiências sociais acerca da brincadeira de bolinhas de sabão e dos diferentes materiais que podem ser usados para fazer bolinhas: "AT: A minha mãe uma vez pegou uma mangueira do chuveirinho e deu um pedaço pra mim e pro meu irmão, e a gente fez bolinha de sabão".

A professora explica como irão confeccionar um aparato individual para brincar e levanta uma questão sobre a forma das bolinhas de sabão.

48. Prof.: Nós vamos usar um fio grosso que a prof. vai trazer e cada criança vai fazer o seu brinquedo, no formato que quiser, pra ver se as bolinhas podem ser de formatos diferentes.

49. Crianças eufóricas: Pode levar pra casa?

50. Prof.: Pode sim.

51. AS: Prof., bolinha de sabão é só redonda.

52. Prof.: Como você sabe disso AS?

53. AS: Porque é bo-li-nha (fala pausada e com ênfase em cada sílaba).

54. AK: Mas se a gente fizer direitinho ela fica de outro jeito.

55. Prof.: Como assim?

56. AK: Se a gente faz o material direito e sopra bem devagar, ela vira de outro jeito.

57. Prof.: Tudo bem, nós vamos fazer o nosso material e vamos descobrir o que vai acontecer. 
Nesse momento, AS contesta a ideia da professora e faz uma justificativa (IAC) usando como garantia o sentido da palavra "bolinha" (turnos 62 e 63). Mesmo diante da convicção demonstrada pela criança nesse momento, AK questiona e mantém a dúvida, apresentando outra hipótese (IAC e CC), o que reforça a importância da investigação proposta pela professora.

\section{CONSIDERAÇÕES FINAIS}

Nos episódios apresentados da SD, observamos que as crianças estavam envolvidas e motivadas para realizar a atividade. Pensamos que muitos fatores contribuíram para esse entusiasmo: o interesse de buscar respostas para as dúvidas levantadas por elas, o aspecto lúdico proporcionado pela realização da atividade concreta e a valorização dos seus pontos de vista quando discutiam sobre o assunto. As crianças entendiam que a atividade fora desencadeada pelo interesse delas.

Vale destacar que os indícios de AC presentes nos registros e discussões da El, analisados à luz dos referenciais escolhidos, também apontam uma resposta positiva sobre o processo analisado.

Segundo Furman (2009, p. 14-15), as CC "não se desenvolvem espontaneamente, é preciso aprendê-las". E esse é um processo progressivo que pode oferecer melhores resultados quando iniciado desde as séries iniciais. Nessa perspectiva, as crianças avançam das competências mais simples (observar e descrever) para as mais complexas (elaborar experimentos e argumentar).

Essa análise nos faz refletir sobre a importância de um ensino de ciências que favoreça a construção das bases do pensamento científico. Ao definir essa ideia, Furman (2009, p. 7) afirma:

Quando falo de estabelecer as bases do pensamento científico estou falando de "educar" a curiosidade natural dos alunos para hábitos do pensamento mais sistemáticos e mais autônomos. Por exemplo, orientando-os a encontrar regularidades (ou raridades) na natureza que os estimulem a fazer perguntas, ajudando-os a elaborar explicações possiveis para o que observam e imaginar maneiras de colocar em prova suas hipóteses; e ensinando-Ihes a trocar ideias com outros, fomentando que sustentem o que dizem com evidências e que as busquem por trás das afirmações que escutam. Trata-se, em suma, de utilizar esse desejo natural de conhecer o mundo que todas as crianças trazem para a escola como plataforma sobre a qual possam construir ferramentas de pensamento que Ihes permitam compreender como as coisas funcionam, e pensar por eles mesmos. E, também, de que o prazer que se obtém ao compreender melhor o mundo alimente a chama de sua curiosidade e a mantenha viva. 
A ideia da autora sustenta a proposta apresentada neste trabalho, e, consideradas as especificidades da faixa etária, acreditamos que a SD analisada serviu para alimentar a curiosidade natural dos pequenos e provocar discussões que, provavelmente, não aconteceriam em outras circunstâncias.

Outro ponto que devemos ressaltar é o papel da professora como mediadora das questões surgidas ao longo da pesquisa. 0 trabalho de constante retomada e organização das ideias dos alunos possibilitou sistematizar as conclusões das crianças.

Para Pozo (2012), a construção de explicações faz parte de um rol de habilidades mentais mais complexas do que as possíveis para as crianças pré-escolares, que, aos poucos, por meio de relações dialógicas com o meio e com seus pares e amparadas pela mediação da linguagem, vão construindo os encadeamentos necessários para o desenvolvimento das habilidades superiores, como explicações e análises. Vale destacar que a realização apenas dessa atividade, considerando a faixa etária das crianças, não nos permite identificar tais habilidades.

Segundo Bernd Fichtner (2010, p. 28),

Na perspectiva de Vigotski cada criança resolve o problema dessa descontinuidade na forma de um "drama". Quer dizer na sua própria atividade cada criança resolve o problema de relacionar e unir numa forma autêntica e irrepetivel três processos na sua vida: o processo da evolução dos seres humanos, o processo histórico da sua sociedade e o processo da sua biografia.

Para além das considerações empíricas relacionadas à SD, o que tornou a atividade possível foi o estabelecimento de um espaço dialógico e respeitoso entre a educadora e as crianças. 0 respeito à capacidade de se encantar cotidianamente com bolas de sabão é o reconhecimento de que as próprias crianças, por meio de suas atividades cotidianas, concepções de mundo e historicidade, criam caminhos potencialmente ricos para dialogar com aspectos da cultura científica.

\title{
Child's play and research sciences in early childhood education
}

\begin{abstract}
This work presents an excerpt from a master's thesis aimed at investigating the possibilities of learning aspects of scientific culture in early childhood education, based on the children's own interests in their games. The material presented here comprises the analysis of a conversation circle in which the teacher proposes to the children to carry out an investigation, based on their memories, considerations and questions about a very common game among them: making soap bubbles. This conversation circle was carried out in the first stage of a didactic sequence elaborated by the teacher based on the observation of the children's actions and enunciations during a game they selected in an art class. From the various questions emerging from this activity, it is possible
\end{abstract}


to verify and demystify concepts and prejudices about childhood, children's thinking and language and their problem-solving capacity. Based on Lev Vygotsky's theory of development and through the identification of evidence of scientific literacy and scientific competence in children's reports, the process highlights the potential of children's play, as well as the important mediating role of the teacher, in introducing the little ones to the universe of sciences and the importance of establishing dialogic spaces in early childhood education.

Keywords: Early childhood education. Skills scientific. Scientific literacy. Conversation circle.Teacher training.

\section{REFERÊNCIAS}

BRASIL. Referencial Curricular Nacional para a Educação Infantil. Brasília: Ministério da Educação e do Desporto, Secretaria de Educação Fundamental, 1998.

BRASIL. Diretrizes Curriculares Nacionais para a Educação Infantil. Brasilia: Ministério da Educação, Secretaria de Educação Básica, 2010.

CARVALHO, M. P. (org.). Ensino de ciências por investigação: condições para implementação em sala de aula. São Paulo: Cengage Learning, 2014.

CRESWELL, J. W. Projeto de pesquisa: métodos qualitativo, quantitativo e misto. Porto Alegre: Artmed, 2010.

DELIZOICOV, D.; LORENZETTI, L. Alfabetização científica no contexto das séries iniciais. Ensaio Pesquisa em Educação em Ciências, v. 3, n. 1, p. 37-50, 2001.

FICHTNER, B. 0 surgimento do novo nos gestos de crianças: um "diálogo impossível" entre Benjamin e Vigotski. Poiesis Pedagógica, v. 8, n. 2, p. 18-32, ago./dez. 2010.

FREIRE, P. Pedagogia da autonomia. São Paulo: Paz e Terra, 1996.

FREIRE, P. A importância do ato de ler: em três artigos que se completam. São Paulo: Autores Associados: Cortez, 1989. (Coleção polêmicas do nosso tempo, v. 4).

FUENTES, S. S. 0 porquê e o como das ciências na educação infantil. Pátio: Educação Infantil, ano $X_{1}$ n. 33, p. 8-11, 2012.

FURMAN, M. O ensino de ciências no ensino fundamental: colocando pedras fundacionais no pensamento científico. São Paulo: Sangari Brasil, 2009.

HUBNER, L. A criança e os conhecimentos sobre a natureza e a sociedade. Avisa Lá, 2001. Disponivel em: http://avisala.org.br/index.php/assunto/conhecendo-a-crianca/a-crianca-eos-conhecimentos-sobre-a-natureza-e-a-sociedade/. Acesso em: 30 ago. 2020.

KLISYS, A. Ciência, arte e jogo: projetos e atividades lúdicas na educação infantil. São Paulo: Peirópolis, 2010. 
MINAYO, M. C. de S. O desafio do conhecimento. São Paulo: Hucitec, 1993.

MINAYO, M. C. de S. (org.). Pesquisa social. Teoria, método e criatividade. 18. ed. Petrópolis: Vozes, 2001.

OLIVEIRA, M. K. de. Coleção grandes educadores: Lev Vygotsky. São Paulo: Paulus, 2006.

PALANGANA, I. C. Desenvo/vimento e aprendizagem em Vygotsky: a relevância do social. 6. ed. São Paulo: Summus, 2005.

POZO, J. I. Educação científica na primeira infância. Pátio: Educação Infantil, v. 10, n. 33, p. 4-7, 2012.

REGO, T. C. Vygotsky: uma perspectiva histórico cultural da educação. 26. ed. Petrópolis, RJ: Vozes, 2014.

SASSERON, L. H.; CARVALHO, A. M. P. de. Almejando a alfabetização científica no ensino fundamental: a proposição e a procura de indicadores do processo. Investigações em Ensino de Ciências, v. 13, n. 3, p. 333-352, 2008.

VELANGA, C. T. Currículo como base para a compreensão do processo educacional: reflexões para a formação do educador. Formação docente e estratégias de integração. Universidade/ Escola nos cursos de Licenciatura. Porto Velho: Edufro, 2008.

VYGOTSKY, L. S. A construção do pensamento e da linguagem. 2. ed. São Paulo: Martins Fontes, 2010.

VYGOTSKY, L. S. A formação social da mente: o desenvolvimento social da mente. São Paulo: Martins Fontes, 2007.

WARSCHAUER, C. Rodas em rede: oportunidades formativas na escola e fora dela. Rio de Janeiro: Paz e Terra. 2001. 